\title{
Use of Systemic Medications for Treating Adult Atopic Dermatitis in France: Results of a Practice Survey
}

This article was published in the following Dove Press journal: Clinical, Cosmetic and Investigational Dermatology

\section{Anne-Claire Fougerousse $\mathbb{D}^{\prime}$ \\ Caroline Jacobzone ${ }^{2}$ \\ Laure Mery-Bossard ${ }^{3}$ \\ Ziad Reguiai ${ }^{4}$ \\ Catherine Droitcourt ${ }^{5}$ \\ Charles Taieb (D) ${ }^{6}$ \\ François Maccari ${ }^{7}$ \\ On behalf of GEM ResoEczema Group}

\begin{abstract}
'Dermatology Department, Hôpital d'Instruction des Armées Bégin, Saint Mandé, Val de Marne, France;

${ }^{2}$ Dermatology Department, Hôpital du Scroff, Groupe Hospitalier Bretagne Sud, Lorient, Morbihan, France; ${ }^{3}$ Dermatology Department, Centre Hospitalier Intercommunal Poissy Saint Germain en Laye, Saint-Germain-en-Laye, Yvelines, France; ${ }^{4}$ Dermatology Department, Polyclinique Courlancy, Reims, Marne, France; ${ }^{5}$ Dermatology Department, Centre Hospitalier Universitaire, Rennes, Ille et Vilaine, France; ${ }^{6}$ Emma Clinic, Fontenay-sous-Bois, Val de Marne, France; ${ }^{7}$ Private Practice, Saint-Maur-desFossés, Val de Marne, France
\end{abstract}

Purpose: Recent studies have illustrated that systemic medications are underused for treating adult atopic dermatitis (AD) and that dermatologists have concerns regarding the safety profile of cyclosporine in AD.

Patients and Methods: We performed a national online practice survey between March and April 2020.

Results: A total of 305 dermatologists responded, 57\% with hospital-based activity and $43 \%$ with private practice. Overall, $46.9 \%$ prescribed cyclosporine for adult AD. Before initiating treatment, $56.9 \%$ did not perform evaluation scoring. Reasons for not prescribing cyclosporine were no eligible patients $(24.7 \%)$, lack of information $(52.6 \%)$, need for hospital prescription (31.2\%), and lack of experience (79.2\%). Fifty-four percent of the dermatologists prescribed methotrexate for adult AD. Before initiating treatment, $50.5 \%$ did not perform evaluation scoring. Reasons for not prescribing methotrexate were no eligible patients (46.7\%), lack of information (39.3\%), lack of experience (25.2\%), and not approved for $\mathrm{AD}(47.4 \%)$. A total of $2.1 \%$ dermatologists prescribed other systemic treatments for adult $\mathrm{AD}, 9.8 \%$ prescribed corticosteroids and $56.4 \%$ prescribed dupilumab.

Conclusion: Systemic treatments for $\mathrm{AD}$ are used by half of dermatologists, although cyclosporine and dupilumab must be initiated in hospitals in France. Methotrexate is more frequently used than cyclosporine, although it is not approved for this indication in France. A vast majority of dermatologists do not perform any evaluation scoring before initiating systemic treatment for adult $\mathrm{AD}$.

Keywords: atopic dermatitis, cyclosporine, methotrexate, practice survey

\section{Introduction}

Adult atopic dermatitis is a frequent chronic inflammatory dermatosis, the prevalence of which is estimated to be $4.65 \%$ in France, ${ }^{1}$ with $68 \%$ of patients having moderate to severe forms. ${ }^{2}$ Its treatment is based on local treatments (emollients, dermocorticoids, topical calcineurin inhibitors) and, in moderate to severe forms, in the event of failure, phototherapy, immunosuppressants (cyclosporine (the only systemic treatment with marketing authorisation for this indication in France), methotrexate, azathioprine, mycophenolate mofetil) and dupilumab. ${ }^{3}$ We are at the dawn of a therapeutic revolution for AD with new treatments like biotherapies targeting IL 13 (tralokinumab, lebrikizumab) or IL 31 (nemolizumab) and Janus Kinase inhibitors (baricitinib, upadacitinib, abrocitinib ...) being developed. ${ }^{4}$
Correspondence: Anne-Claire Fougerousse Dermatology Department, Hôpital d'Instruction des Armées Bégin, Saint Mandé, Val de Marne, France

Email ac.fougerousse@gmail.com 
In France, only dermatologists with hospital activity can initiate cyclosporine and dupilumab, and private dermatologists can only renew these treatments. In 2017, a French study showed that systemic treatments for atopic dermatitis were underprescribed, since in a cohort of 401 patients, $73 \%$ had a moderate to severe form, while only $8 \%$ were receiving systemic treatment. ${ }^{5}$ Dermatologists have also expressed concerns about the safety profile of cyclosporine for this indication. ${ }^{6}$ We evaluated the modalities of the use of systemic treatments for adult atopic dermatitis in France.

\section{Patients and Methods}

We conducted a practice survey among ResoEczema member dermatologists by means of a questionnaire sent by e-mail (with two reminders) between March and April 2020.

\section{Questionnaire}

The questionnaire collected the gender of the dermatologist, the year the thesis was obtained, the mode of practice (hospital, private or mixed), and the prescription of cyclosporine, methotrexate, general corticosteroids, other immunosuppressants and dupilumab for adult atopic dermatitis. The questionnaire collected information on how the treatments were prescribed (severity scores, treatment line, dose and duration of treatment, monitoring methods) and, if necessary, the reasons for not using these treatments. For this type of study, French regulations do not require submission to an ethics committee, as this study does not enter the field of the deliberation $n^{\circ} 2018-154$ of the $3^{\text {rd }}$ of May 2018 (JORF $n^{\circ} 0160$ of the 13th of July 2018).

\section{Statistics}

Quantitative data are expressed as the average \pm standard deviation (SD), and qualitative data are expressed as headcount (\%). Means were compared using Student's $t$-test, and frequencies were compared with the Chi2 test. A value of $\mathrm{p}<0.05$ was considered statistically significant. Statistical analyses were performed using R software version 3.5.1.

\section{Results}

\section{Characteristics of the Dermatologists}

Three hundred five dermatologists answered the questionnaire, representing 9\% [source JO Sénat du 11/12/2014 page 2726] of French dermatologists. The average length of practice since the thesis was 19 years +-9.98, 202 (66.2\%) were women, 87 (28.5\%) practised in hospitals, $131(42.9 \%)$ practised in private practice and $87(28.5 \%)$ had a mixed practice. There was no difference in the length of practice between self-employed dermatologists and dermatologists with hospital activity (hospital and mixed).

\section{Prescription of Cyclosporin}

One hundred thirty-six dermatologists $(46.9 \% / 290)$ prescribed cyclosporine for adult atopic dermatitis. This drug was used as a first-line systemic treatment in $77.2 \%$ of cases and as a second-line treatment in $31.6 \%$ of cases. A total of $46.3 \%$ of dermatologists prescribed it for moderate atopic dermatitis and $99.3 \%$ for severe atopic dermatitis. The daily doses prescribed were $3 \mathrm{mg} / \mathrm{kg}$ in $42.6 \%$ of cases, $5 \mathrm{mg} / \mathrm{kg}$ in $36 \%$ of cases, $2.5 \mathrm{mg} / \mathrm{kg}$ in $16.9 \%$ of cases, and other in $4.41 \%$ of cases. Biological monitoring was carried out every month $(75.7 \%)$, every 2 months (9.56\%), every 3 months (2.9\%), and at other monitoring rates $(11.8 \%)$. The average durations of treatment were less than 3 months $(9.6 \%)$, from 3 to 6 months (51.5\%), from 6 months to 1 year (36.8\%), and more than 1 year $(2.2 \%)$. A total of $56.9 \%$ of dermatologists did not perform any evaluation scoring before the initiation of cyclosporine, 7.9\% performed the Investigator Global Assessment (IGA), 23.8\% performed the Scoring Atopic Dermatitis (SCORAD), 13.4\% performed the Eczema Activity and Severity Index (EASI), 17.2\% evaluated the affected body surface area (SCA) and 34.8\% performed the Dermatology Life Quality Index (DLQI).

Among the 154 dermatologists who not prescribing cyclosporine for adult atopic dermatitis, the reasons given were the absence of eligible patients $(n=38$, $24.7 \%$ ); the fact that the product is not covered by a marketing authorization, $\mathrm{n}=3(1.9 \%)$; a lack of knowledge of the recommendations, $\mathrm{n}=15(9.7 \%)$; a lack of information and training, $\mathrm{n}=81(52.6 \%)$; the need for an initial hospital prescription, $\mathrm{n}=48(31.2 \%)$; and a lack of experience, $\mathrm{n}=122(79.2 \%)$.

\section{Prescription of Methotrexate}

One hundred fifty-eight dermatologists $(53.9 \% / 293)$ prescribed methotrexate for adult atopic dermatitis. This drug was used as a first-line systemic treatment in $47.4 \%$ of cases, as a 2 nd line or above treatment in $47.4 \%$ of cases, and after failure of dupilumab in $26.6 \%$ of cases. A total of $1.3 \%$ of dermatologists prescribed it for mild atopic 
dermatitis, with $50 \%$ and $98.8 \%$ prescribing it for moderate and severe atopic dermatitis, respectively. The prescribed weekly doses were $15 \mathrm{mg}$ in $48.4 \%$ of cases, $20 \mathrm{mg}$ in $41.4 \%$ of cases, $25 \mathrm{mg}$ in $4.5 \%$, and other in $5.7 \%$ of cases. In the event of an insufficient response, the dosage was increased in $70.2 \%$ of cases. Biological monitoring was carried out every month (26\%), every 2 months (19\%), every 3 months (31.6\%), and with other monitoring rhythms (23.4\%). A total of $50.5 \%$ of dermatologists did not perform any evaluation scoring before methotrexate initiation, $7.8 \%$ performed IGA, 28.3\% performed SCORAD, 13\% performed EASI, 17\% performed SCA and 38.9\% performed DLQI.

Among the 135 dermatologists not prescribing methotrexate for adult atopic dermatitis, the reasons given were as follows: no eligible patients, $n=63(46.7 \%)$; no MA in this indication, $n=34$ (47.4\%); a lack of information and training, $\mathrm{n}=53(39.3 \%)$; and a lack of experience, $\mathrm{n}=34(25.2 \%)$.

\section{Prescription of Other Treatments}

A total of $4.8 \%$ of dermatologists (14/280) prescribed other systemic treatments for adult atopic dermatitis, such as phototherapy, $\mathrm{n}=10$; azathioprine, $\mathrm{n}=5$; and mycophenolate mofetil, $\mathrm{n}=3$.

A total of $9.8 \%$ of dermatologists $(n=28 / 287)$ prescribed systemic corticosteroids for adult atopic dermatitis in moderate $(17.9 \%)$ or severe $(96.4 \%)$ forms. The dosages were $<0.5 \mathrm{mg} / \mathrm{kg} /$ day in $21.4 \%$ of cases and 0.5 to $1 \mathrm{mg} / \mathrm{kg} /$ day in $78.6 \%$ of cases. The average durations of treatment were less than 7 days in $32.1 \%$ of cases, from 7 to 30 days in $64.3 \%$ of cases, more than 1 month in $3.6 \%$ of cases, and other in $3.6 \%$ of cases.

A total of $56.4 \%$ of dermatologists prescribed dupilumab for atopic dermatitis in adults, with initial prescription in $71.4 \%$ of cases and exclusive renewal in $28.6 \%$ of cases.

Table 1 presents the results according to the mode of practice (hospital/mixed and private practice).

\section{Discussion}

Systemic treatments for atopic dermatitis are used by half of the dermatologists who responded to this practice survey. Methotrexate is more commonly used than cyclosporine, although it does not have marketing authorisation for this indication. This illustrates a certain reluctance to use cyclosporine due to fear of side effects, the lack of experience of dermatologists with this medication, and the need for an initial hospital prescription, among other factors. The greater familiarity with the prescription of methotrexate may also explain its extensive use.

There are differences in practice between private and hospital/mixed practice dermatologists, the latter prescribing more cyclosporine and dupilumab in the expected manner since they require an initial hospital prescription and more methotrexate. Similarly, the scores were used much less by private dermatologists than by hospital/ mixed dermatologists before the initiation of systemic treatment, probably due to a lack of habit and lack of time.

This underuse of cyclosporine is also found in other countries.

In a practice survey conducted in 2013 in the United Kingdom, cyclosporine was less commonly used $37.4 \%$ of dermatologists) than other oral systemic treatments, such as azathioprine (51.2\%) and general corticosteroid therapy $(42.9 \%)$, whereas only cyclosporine had marketing authorisation for this indication in the United Kingdom at the time. According to the authors, the maximum recommended duration of treatment of one year for cyclosporine explained the choice of azathioprine, which can be used for longer periods. ${ }^{7}$

In a recent Australian survey, 22\% of dermatologists surveyed had never used cyclosporine. Phototherapy (72\%) and methotrexate $(15 \%)$ were preferred to cyclosporine $(9 \%)$ in the event of topical treatment failure. The durations of prescription of cyclosporine were less than 6 months in $7 \%$ of cases, 6 to 12 months in $24 \%$ of cases and more than 12 months in $69 \%$ of cases. The dose used was more than $5 \mathrm{mg} / \mathrm{kg} /$ day in $1 \%$ of cases, from 3.5 to $5 \mathrm{mg} . \mathrm{kg} /$ day in $42 \%$ of cases and less than $3.5 \mathrm{mg} / \mathrm{kg} /$ day in $56 \%$ of cases. ${ }^{6}$

In our study, almost $10 \%$ of dermatologists prescribed short courses of general corticosteroid therapy for adult atopic dermatitis. Its use should be limited to patients with a severe form, at a dose of less than $0.5 \mathrm{mg} / \mathrm{kg} /$ day and with a maximum duration of 8 days. ${ }^{8}$ The need for repeated use illustrates the severity of atopic dermatitis and the need for specific systemic treatment. ${ }^{9}$

It should be noted that the proportion of dermatologists prescribing dupilumab is higher than those prescribing cyclosporine or methotrexate. This reflects an interest in new therapies for atopic dermatitis as well as a tolerance profile and manageability considered superior to that of systemic treatments.

The majority of dermatologists do not use an assessment score before initiating systemic treatment for adult 
Table I Results by Mode of Exercise (Hospital and Mixed Practice/Private Practice)

\begin{tabular}{|c|c|c|c|}
\hline & Hospital/Mixed Practice $(n=175)$ & Liberal Practice $(n=|3|)$ & Chi Square \\
\hline Prescription of methotrexate & $\begin{array}{l}68.9 \%(n=115 / 167) \\
\text { MD: } 8\end{array}$ & $\begin{array}{l}34.6 \%(n=44 / 127) \\
\text { MD: } 4\end{array}$ & $\leq 0.001$ \\
\hline $\begin{array}{l}\text { Reason for not prescribing methotrexate } \\
\text { - Absence of eligible patients } \\
\text { - No marketing authorisation for AD } \\
\text { - No experience with methotrexate } \\
\text { - Lack of training/information }\end{array}$ & $\begin{array}{l}n=52 \\
-57.7 \%(n=30 / 52) \\
-46.1 \%(n=24 / 52) \\
-9.6 \%(n=5 / 52) \\
-21.1 \%(n=11 / 52)\end{array}$ & $\begin{array}{l}n=83 \\
-39.8 \%(n=33 / 83) \\
-48.2 \%(n=40 / 83) \\
-34.9 \%(n=29 / 83) \\
-50.6 \%(n=42 / 83)\end{array}$ & \\
\hline Prescription of cyclosporine & $\begin{array}{l}75.1 \%(n=124 / 165) \\
\text { MD: } 10\end{array}$ & $\begin{array}{l}10.3 \%(n=13 / 126) \\
\text { MD: } 5\end{array}$ & $\leq 0.001$ \\
\hline $\begin{array}{l}\text { Reason for not prescribing cyclosporine } \\
\text { - Absence of eligible patients } \\
\text { - Lack of knowledge of the recommendations } \\
\text { - No experience with cyclosporine } \\
\text { - Lack of training/information } \\
\text { - Requires initial hospital prescription }\end{array}$ & $\begin{array}{l}n=4 I \\
-26.8 \%(n=|| / 4 \mid) \\
-0 \\
-78 \%(n=32 / 4 I) \\
-4 I .5 \%(n=|7 / 4|) \\
-4.9 \%(n=2 / 4 I)\end{array}$ & $\begin{array}{l}n=113 \\
-23.9 \%(n=27 / 113) \\
-13.3 \%(n=15 / 113) \\
-79.6 \%(n=90 / 113) \\
-56.6 \%(n=64 / 113) \\
-40.7 \%(n=46 / 113)\end{array}$ & \\
\hline Prescription of oral corticoids & $\begin{array}{l}7.9 \%(n=13 / 164) \\
\text { MD: } 9\end{array}$ & $\begin{array}{l}12.1 \%(n=15 / 124) \\
\text { MD: } 7\end{array}$ & NS \\
\hline Prescription of dupilumab & $\begin{array}{l}80.5 \%(n=132 / 167) \\
\text { MD: } 8\end{array}$ & $\begin{array}{l}25 \%(n=3|/| 24) \\
\text { MD: } 7\end{array}$ & $\leq 0.00 \mathrm{I}$ \\
\hline Absence of use of score before methotrexate prescription & $\begin{array}{l}39.5 \%(n=66 / 167) \\
\text { MD: } 8\end{array}$ & $\begin{array}{l}64.6 \%(n=82 / / 27) \\
\text { MD: } 4\end{array}$ & $\leq 0.001$ \\
\hline Absence of use of score before cyclosporine prescription & $\begin{array}{l}35.1 \%(n=58 / 165) \\
\text { MD: } 10\end{array}$ & $\begin{array}{l}84.9 \%(n=107 / 126) \\
\text { MD: } 5\end{array}$ & $\leq 0.001$ \\
\hline
\end{tabular}

Abbreviations: $M D$, missing data; $A D$, atopic dermatitis, NS, not significant.

atopic dermatitis. This makes it more difficult to assess the severity of atopic dermatitis and the effectiveness of treatments. Lack of familiarity with atopic dermatitis assessment scores (SCORAD, EASI, Patient Oriented Eczema Measure, etc.) and the absence of a consensus definition of the severity of atopic dermatitis, unlike other chronic inflammatory dermatoses such as psoriasis, may explain this low use.

\section{Conclusion}

Our study showed that half of French dermatologists use systemic treatments in topical dermatitis in adults. Methotrexate is used more than cyclosporine, probably due to greater familiarity with this medication and the absence of an initial hospital prescription. Dupilumab, although more recently available, is already quite widely used. Our study also highlights an underutilisation of assessment scores for atopic dermatitis prior to the introduction of systemic treatments.

\section{Acknowledgments}

Funding source received from Pfizer laboratory. The abstract of this paper was presented at the $29^{\text {th }}$ European Academy of Dermatology and Venerology and at the Journées Derrmatologiques de Paris 2020 as a poster presentation with interim findings. The poster's abstract was published in "Poster Abstracts" in the Annales de Dermatologie et de Vénéréologie, 147, Suppl Dec 2020.

\section{Disclosure}

Dr Laure Mery-Bossard reports personal fees from sanofi, during the conduct of the study; personal fees and/or nonfinancial support from Abbvie, Janssen, Novartis, Leo pharma, outside the submitted work. Dr Ziad Reguiai is consultant, advisory board member, speaker and/or investigator for SANOFI, Lilly, Abbvie, MEDAC, PFIZER, PIERRE FABRE DERMATOLOGIE, LA ROCHE POSAY, CERAVE, Leo Pharma, and ALMIRALL, during the conduct of the study. The authors report no other conflicts of interest in this work. 


\section{References}

1. Richard MA, Corgibet F, Beylot-Barry M, et al. Sex- and age-adjusted prevalence estimates of five chronic inflammatory skin diseases in France: results of the OBJECTIFS PEAU study. $J$ Eur Acad Dermatol Venereol. 2018;32(11):1967-1971. doi:10.1111/jdv.14959

2. Barbarot S, Auziere S, Gadkari A, et al. Epidemiology of atopic dermatitis in adults: results from an international survey. Allergy. 2018;73(6):1284-1293. doi:10.1111/all.13401

3. Wollenberg A, Barbarot S, Bieber T, et al. Consensus-based European guidelines for treatment of atopic eczema (atopic dermatitis) in adults and children: part I [published correction appears in J eur acad dermatol venereol]. J Eur Acad Dermatol Venereol. 2018;32(5):657-682. doi: $10.1111 / j \mathrm{dv} .14891$

4. Dattola A, Bennardo L, Silvestri M, Nisticò SP. What's new in the treatment of atopic dermatitis? Dermatol Ther. 2019;32(2):e12787. doi: $10.1111 /$ dth. 12787
5. Pascal C, Maucort-Boulch D, Gilibert S, et al. Therapeutic management of adults with atopic dermatitis: comparison with psoriasis and chronic urticaria. $J$ Eur Acad Dermatol Venereol. 2020;34 (10):2339-2345. doi:10.1111/jdv.16329

6. Phan K, Charlton O, Baker C, et al. Dermatologist attitudes toward ciclosporin use in atopic dermatitis. J Dermatol Treat. 2020;10:1-3. doi:10.1080/09546634.2020.1724251

7. Taylor K, Swan DJ, Affleck A, et al. Treatment of moderate-to-severe atopic eczema in adults within the U.K.: results of a national survey of dermatologists. Br J Dermatol. 2017;176(6):1617-1623. doi:10.1111/ bjd. 15235

8. Wollenberg A, Barbarot S, Bieber T, et al. Consensus-based European guidelines for treatment of atopic eczema (atopic dermatitis) in adults and children: part II. J Eur Acad Dermatol Venereol. 2018;32 (6):850-878.

9. Lacour JP. Les traitements systémiques de la dermatite atopique. Ann Dermatol Venéréol. 2019;146(12):12S76-12S84. doi:10.1016/S01519638(20)30017-X

\section{Publish your work in this journal}

Clinical, Cosmetic and Investigational Dermatology is an international, peer-reviewed, open access, online journal that focuses on the latest clinical and experimental research in all aspects of skin disease and cosmetic interventions. This journal is indexed on CAS.
The manuscript management system is completely online and includes a very quick and fair peer-review system, which is all easy to use. Visit http://www.dovepress.com/testimonials.php to read real quotes from published authors. 